\title{
FAULT TOLERANT SYSTEM DESIGN BASED FUZZY OBSERVER
}

\author{
Yihu Huang ${ }^{1}$, Guangxin Zhang ${ }^{2}$, Ximei Jia ${ }^{3}$ \\ ${ }^{1}$ College of Automation and Electron Engineering, Qingdao University of Science and \\ Technology,China; Email: hyhuzi@163.com. ${ }^{2}$ Control Science and Engineering Department, \\ Zhejiang University, China. ${ }^{3}$ College of Electromechanical Engineering, Qingdao Science \\ and Technology, China
}

\begin{abstract}
Crude oil in the pipeline evaporation is one of hidden safety trouble for directly-fired kiln, which maybe be caused by severe flame deflecting. According to redundancy between technology parameters of furnace, redundancy select majority strategy was proposed, and used as the inference rule of fuzzy observer, the output of the fuzzy observer was tendency of furnace working condition, then it compared with deviation of other local input parameters to diagnose effectively fire deflect and sensors fault. Thus safety and fault-tolerant capacity of furnace are improved, and stronger robustness is also obtained.
\end{abstract}

Key words: Furnace, Fuzzy Observer, Fault-Tolerant System

\section{INTRODUCTION}

Large long-distance pipeline transferring system is main mode of crude oil storage and transportation in China, direct furnace is one of three main parts of it. Crude oil pipeline is laid down along two side of furnace. So there are separately two crude oil temperature of inlet and outlet. This means there are several incipient faults during furnace operation.

Incipient fault one: Ejection gun is fixed in front of furnace by bolts. It has rather shock during working. After long running, the fixed bolt probably shock loose; this can make severe blaze deflection, and cause oil gasification accident. Some protective measures was designed to avoiding the accident, such as alarm or shutdown furnace, if crude oil temperature on the left or

Please use the following format when citing this chapter:

Huang, Yihu, Zhang, Guangxin, Jia, Ximei, 2006, in International Federation for Information Processing (IFIP), Volume 207, Knowledge Enterprise: Intelligent Strategies In Product Design, Manufacturing, and Management, eds. K. Wang, Kovacs G., Wozny M., Fang M., (Boston: Springer), pp. 797-802. 
right side of furnace is high $\left(>70^{\circ} \mathrm{C}\right)$; Alarm or shutdown furnace if crude oil pipeline temperature in the left or right side of furnace is high $\left(>350^{\circ} \mathrm{C}\right)$, and so on. But because the furnace is a severe inertia system, above protective measures can not absolutely prevent oil gasification accident.

Incipient fault two: Sensor fault happen in industry field engineering; electromagnetism disturbs impact accuracy of acquisition data either, they all probably cause furnace fluctuating or shutting down.

\section{FUZZY OBSERVER DESIGN}

Furnace is a long time-lag non-linear system, which its multi-input and multi-output are strong-coupling. Those characteristic make automatic control difficulties. We also can use it to design a fuzzy observer.

Furnace meets the necessity of heat transfer theory and dynamic thermal balance principle. Flux diversification of fuel or combustion-supporting air can change working condition of furnace, cause a serious of movement of technic index, which include hearth temperature, pipeline temperature on the left and right side of furnace, outlet temperature on the left and right side of furnace. It means those parameters contain redundancy information each other. When sensors are not faulty and there are not disturb in acquisition data, above 7 measure parameters all reflect hearth combustion in different level, they are local parameter of working condition of furnace.

Base on above analyzing, a fuzzy observer was designed to solve above incipient faults and realize fault-tolerant control.

\subsection{Fuzzy Interface}

Fuzzy interface change real measured value to fuzzy vector. In the industry system, fuzzification gradation is not suitable to divide meticulous, otherwise some information would be lose, and the advantage of fuzzy value could not be utilized (King, 1975). Because the major aid of fuzzy observer is to judge trend of furnace condition, fuzzy input and out variable $e$ is divided by:

$$
e=\{\text { Negative, } \text { Zero, Positive }\}=\{\mathrm{N}, \mathrm{Zo}, \mathrm{P}\}
$$

Because flow control valve of fuel are one-to-one correspondence with fuel flow, fuel valve can substitute fuel flow to be an input parameter of fuzzy observer. 

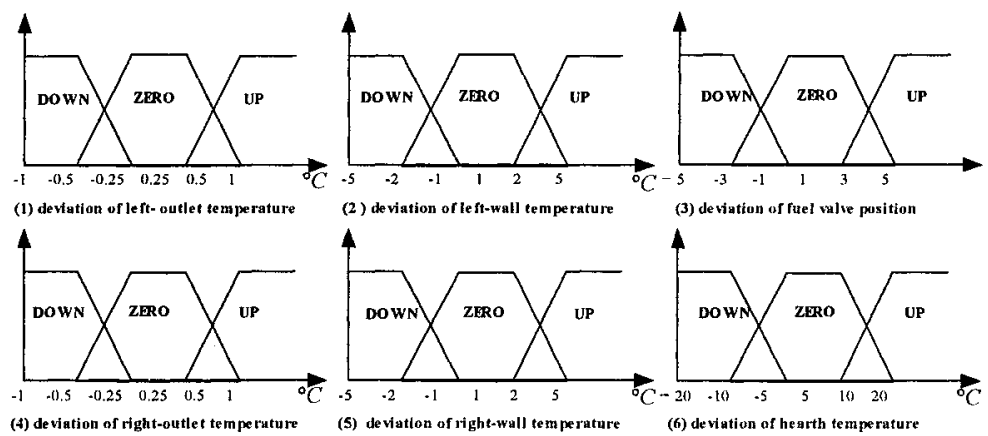

Figure 1. Membership function of input parameters

\subsection{DB-Data Base}

The design chooses trapezoidal membership function as input parameter function of fuzzy observer, and stores them in data base. The data base provides data when system solves equation of fuzzy relation (Lee, 1990).

Fig. 1 shows 6 input parameters of membership function. Valves of the nodal point are defined by multi-trial. Definite principles are as follows:

(1) Considering measured precision of temperature sensor and valve transducer to prevent misjudging;

(2) Considering output precision of fuzzy observer to prevent underreporting.

\subsection{Rule of Fuzzy Observer}

Base on expert knowledge, rule of the fuzzy observer is a kind language form matching instinct inference. It is usually connected by a series of relative, such as if-then, else, also, end, and. All fuzzy rules store in rule base. Rule base and data base compose knowledge base of fuzzy observer.

\subsection{Inference and Defuzzy-Interface}

Consider the process of fuzzy observation as follow:

According to input fuzzy value, rule of fuzzy observer fulfill fuzzy inference, then solve equation of fuzzy relation, and acquire fuzzy observation output. Inference and the part that provides conversion function are called defuzzy-interface (Zhujin, 1995). Output parameter is defined as tendency of working condition of furnace.

Routine Zadeh approximate forward reference (Zedeh,1965) is: 
$R^{i}:$ If $x_{1}$ is $A_{1}^{i}$ and $x_{2}$ is $A_{2}^{i} \ldots$. and $x_{n}$ is $A_{n}^{i}$ then $y$ is $B^{i}$

If several sensors are faulty, the integral tendency from (1) is incorrect. Inference rule of select majority based redundancy of input parameters was put forward as follows:

$$
\begin{aligned}
& R^{i}: \text { If } x_{1} \text { is } A_{1}^{i} \text {, then } N_{1}^{i}=1 \text {; } \\
& x_{2} \text { is } A_{2}^{i} \text {, then } N_{2}^{i}=1 \text {; } \\
& \ldots \ldots \text {; } \\
& x_{6} \text { is } A_{6}^{i} \text {, then } N_{6}^{i}=1 .
\end{aligned}
$$

Where, $i=\left\{\begin{aligned}-1 & \text { when } A_{j}^{i}=-1 \\ 0 & \text { when } A_{j}^{i}=0, j=1,2 \ldots, 6 ; \\ 1 & \text { when } A_{j}^{i}=1\end{aligned}\right.$

If $\sum_{\mathrm{j}=1}^{6} N_{j}^{-1} \geq 4$ then $\mathrm{y}=-1$

If $\sum_{\mathrm{j}=1}^{6} N_{j}^{0} \geq 4$ then $\mathrm{y}=0$

If $\sum_{j=1}^{6} N_{j}^{1} \geq 4$ then $\mathrm{y}=1$

Where $x_{1}, \ldots, x_{6}$ are input parameters of fuzzy observer, $A_{j}^{i}$ is fuzzy value of number $j$ input parameter, $\mathrm{y}$ is output result of fuzzy observer.

Above inference principle of select majority based redundancy of input parameters firstly accumulate separately numbers of input parameter fuzzy value equal to $-1,0$ and 1 , if numbers of one fuzzy value $>=4$, then fuzzy 
observer output this fuzzy value. This means even if one or two of 6 input parameters is faulty, accurate tendency of working condition of furnace can be obtained by redundancy select majority principle.

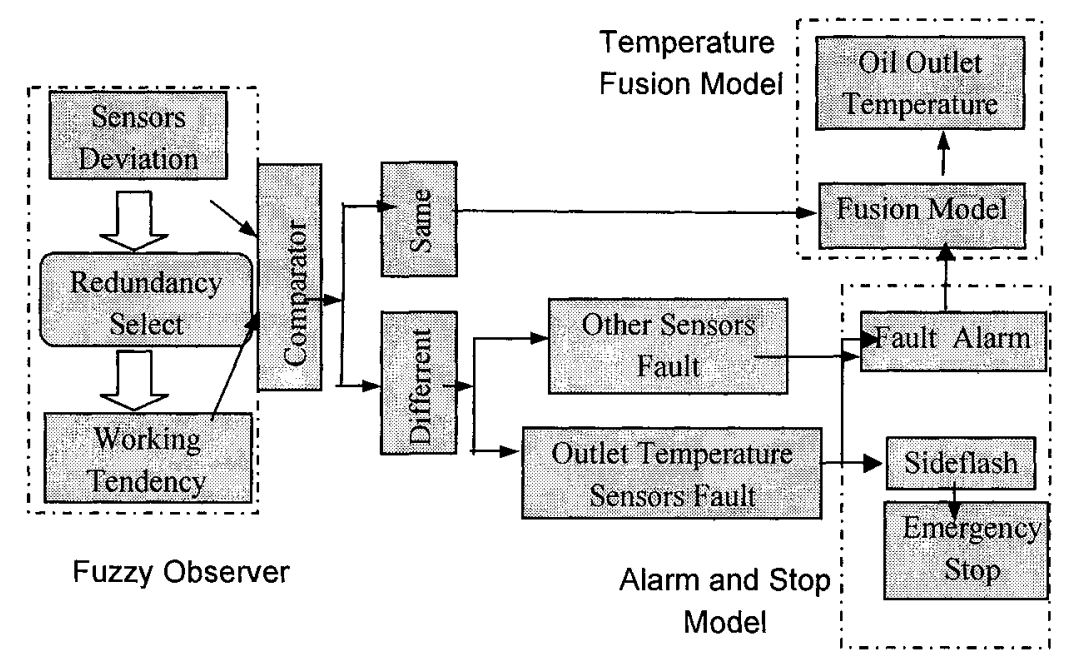

Figure 2. Process Chart of Fault Diagnosis

\section{FAULT DIAGNOSIS PROCESS}

Fig.2 shows implementation procedure of fault diagnosis. Fault Diagnosis include three parts, part 1 is Fuzzy Observer, which deduce the working tendency of furnace; part 2 is Alarm and Stop Furnace Model, which alarm and stop furnace when sensors is faulty; part 3 is oil outlet temperature fusion model, which include dual fusion model and simple fusion model.

In the comparator, 6 input parameter deviation separately compare with tendency of working condition of furnace, if tendencies are identical, then to go to model of double-fusion, to calculate crude oil temperature of furnace outlet (Huang, et al., 2004); otherwise judge whether the parameter is outlet crude oil temperature on the left(or right) side of furnace, if answer is no, judge that the sensor is faulty, and alarm; if answer is yes, then judge whether tendency of crude oil temperature on outlet is same with crude oil pipeline on the same side, if trend is same, define $n=1$; Otherwise $n=0$, then to judge temperature sensor of furnace outlet is faulty, and at same time, to 
go to simple temperature fusion model of furnace outlet. If $n=3$, then to judge flame deflection, and to stop furnace urgently.

\section{CONCLUSION}

The field test shows the method can not only deal with conflict information gathered from different sensors and information of fault sensors, which ensures reliability of furnace, but also overcome safe incipient fault two. In the simple fusion model, the faulty sensor is abandoned, so that accuracy of outlet temperature is assured, and fault-tolerant capacity is improved. Because the method based on the dynamic characteristic of system, the method can abroad apply to other dynamic system, which the parameters are strongly-couple.

\section{REFERENCES}

1. YiHu Huang and ZeKui Zhou, Other (2004). Application of Deviation Parameter Fuzzy Fusion Method in Furnace. In: 3rd International Symposium on Instrumentation Science and Technology, 224-227, Harbin Institute of Technology Press, Harbin.

2. WANG Fang, LIU Yan, SHAO Jun-peng. (2001), The Application of Muti-sensor Combination Technology, JOURAL HARBIN UNIV. SCI. \& TECH, 1(6): 81-84

3. Lee C C (1990), Fuzzy Logic in Control Systems: Fuzzy Logic Controller. In Part 1. IEEE Trans. SMC. 20(2): 404-418

4. LUO Zhang-liang, FANG Qing-cheng, ZHANG Qian-jin. (2002). Method of Data Fusion for Multi-Sensor and its Application, Journal of Transducer Technology, 2 (21): $27-29$

5. King P J and Other (1975). The Application of Fuzzy Control System to Industrial Processes. In IFAC world Congress. MIT. Boston. 132-127.

6. Zadeh L A. (1965). Fuzzy Sets. In Information and Control, 8: 338-353.

7. Zhujin, et (1995) , Fuzzy Control Principle and Application. Publishing Company of Engineering Industry. 